\title{
Metastatic Adrenal Cortex Carcinoma
}

National Cancer Institute

\section{Source}

National Cancer Institute. Metastatic Adrenal Cortex Carcinoma. NCI Thesaurus. Code C156070.

A carcinoma that arises from the adrenal cortex and has metastasized to another anatomic site. 